\title{
Preparation, properties and application of sapphire single-crystal fibers grown by the EFG method
}

\author{
M. Klejch ${ }^{1}$, M. Němec ${ }^{2}$, J. Kubát ${ }^{1}$, and J. Polák ${ }^{1}$ \\ ${ }^{1}$ CRYTUR, Palackého 175, 51101 Turnov, Czech Republic \\ ${ }^{2}$ Faculty of Nuclear Sciences and Physical Engineering, Czech Technical University in Prague, Břehová 7, \\ 11519 Prague, Czech Republic
}

\begin{abstract}
Sapphire - the single crystal of aluminum oxide $\left(\mathrm{Al}_{2} \mathrm{O}_{3}\right)$ - is one of the most important artificially produced materials. The sapphire fibres studied were grown in Crytur using the "edge-defined film-fed growth" (EFG) technique. Their unique physical and chemical properties can be employed in various applications. Due to their high refractive index and a broad transmission band spanning the ultraviolet, visible and infrared bands, sapphire fibres are perfect waveguides in harsh environments. The current major applications are Er:YAG laser beam delivery and pyrometric and spectrometric measurements in furnaces, combustion engines, etc. In this paper we summarize an adjustment of the EFG method to grow thin filaments by giving possible molybdenum die designs. We investigated the fibres using an optical microscope and measured their transmission of an Er:YAG laser beam $(2.94 \mu \mathrm{m})$. The attenuation of the tested samples is approximately $0.1 \mathrm{~dB} / \mathrm{cm}$.
\end{abstract}

\section{Introduction}

Sapphire is a versatile material with plenty of applications due to its material properties [1]. Typically sapphire is grown as bulk crystal by Verneuil, Czochralski or Kyropoulos methods. However $\mathrm{Al}_{2} \mathrm{O}_{3}$ is a very hard material (Mohs 9). Consequently, machining this material is quite difficult and expensive. Therefore crystal growth techniques with minimum post-processing treatment are an efficient way to produce profiled crystals.

The first growth of profiled single crystal sapphire was published more than 40 years ago by La Belle and Mlavsky (TYCO laboratories) [2]. The "edge-defined film-fed growth" (EFG) method is in principle similar to an older one (1953) of A. V. Stepanov for growth of shaped single crystals of metals [3]. Main advantages of the EFG method are growth of near net shape which demands zero or small need of machining, possibility of growth of complicated shapes and large scale profiles, higher growth rate and also automated process control. Sapphire profiles can be prepared by EFG method in various shapes: rods, tubes, plates, ribbons, etc. Review of modern modifications of EFG and related methods was published $[1,4]$. Currently, there exist three commercially used technologies to produce single-crystal fibres of optical quality. The U.S. producer Photran employs the EFG [5-6], the French company Fibercryst uses the "micro-pulling-down" ( $\mu$-PD) technique [7] and the U.S. firm MicroMaterials or University di Pisa utilizes the "laser-heated pedestal growth" (LHPG) method [8].

\section{EFG crystal growth method}

Sapphire fibre production in Crytur is achieved via the EFG technique. The principle of this crystal-frommelt pulling process is that the melt rises through a die, due to capillary effects, from the heated crucible into a small basin of a defined shape, wherefrom the singlecrystal filament is slowly drawn. As the base material we used crushed Verneuil sapphire of $5 \mathrm{~N}$ purity. Molybdenum dies were employed to produce fibres 200 $500 \mu \mathrm{m}$ thick and up to $1500 \mathrm{~mm}$ long. The crystals were pulled at a rate of $60-300 \mathrm{~mm} / \mathrm{h}$. The diameter variation was within $10 \mu \mathrm{m}$ throughout the whole filament.

Figure 1 shows the two principal designs of the dies which supply the raw material to the crystal-melt interface. The first mechanism is a thin capillary through a cylindrical block of molybdenum. This die was machined on a turning lathe and the central hole was achieved via spark erosion using a DIEL MS 5000 metalworking fluid and $0.1 \mathrm{~mm}$ thick tungsten electrode. In the second design, the melt rises in channels grooved into the die surface.

The top-most area of the dies, wherefrom the sapphire crystal is drawn, has to be of a precisely defined shape, i.e., circular for fibres, and with very sharp edges, otherwise the EFG process would not result in the

This is an Open Access article distributed under the terms of the Creative Commons Attribution License 2.0, which permits unrestricted use, distribution, and reproduction in any medium, provided the original work is properly cited. 
required single-crystal filaments. The diameter of the grown fibre is more or less determined by the size of the head of the die. That should be slightly bigger than the crystal thickness. If the difference between the die-top diameter and fibre diameter is significant, which can result from overheating the hot zone of the furnace, then the resulting fibre does not keep the defined circular shape, but crystallizes in a natural way forming a hexagonal filament, cf. figure 2 .

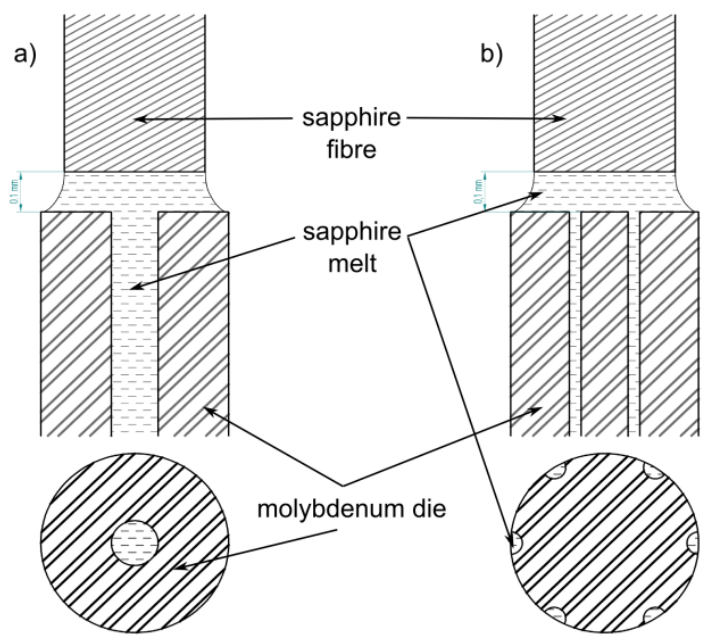

Figure 1. The two principal designs of the molybdenum dies.

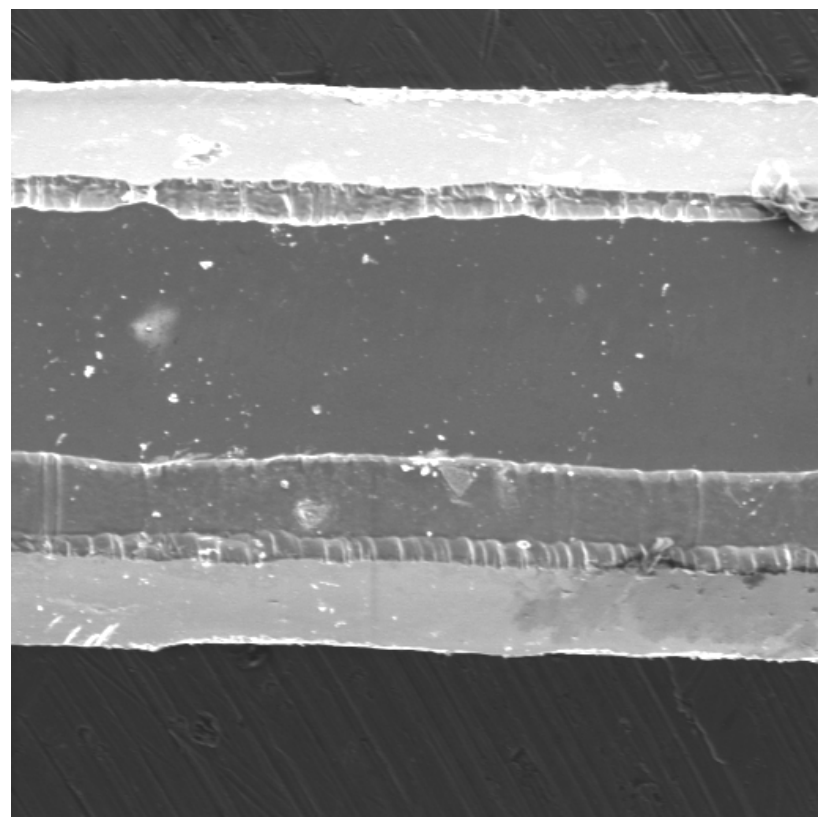

Figure 2. Hexagonal structure of a sapphire fibre caused by overheating the die (SEM image of a $200 \mu \mathrm{m}$ thick single crystal).

\section{Material properties and applications}

Sapphire fibres exhibit extraordinary mechanical durability and maintain their shape and strength even at very high temperatures - up to $2000{ }^{\circ} \mathrm{C}$ (the melting point is $2053{ }^{\circ} \mathrm{C}$ ). They are hard but still show some flexibility and can be bent at a radius approximately $200 \times$ the filament diameter. The high purity of the single-crystal and a lack of defects lead to very high optical transmission over a broad spectrum of wavelengths.
Thanks to the absence of hydroxyl groups in single crystal sapphire, which cause energy absorption in silica fibres, the transmittance of bulk sapphire is almost $100 \%$ for wavelengths of $0.3-5 \mu \mathrm{m}$. The values of $80-90 \%$ from the measurement depicted on figure 3 are caused by surface reflection. The refractive index of sapphire, equal to 1.786 at the sodium D-line, is higher than of many other optical materials. All this makes sapphire the perfect candidate for waveguide applications.

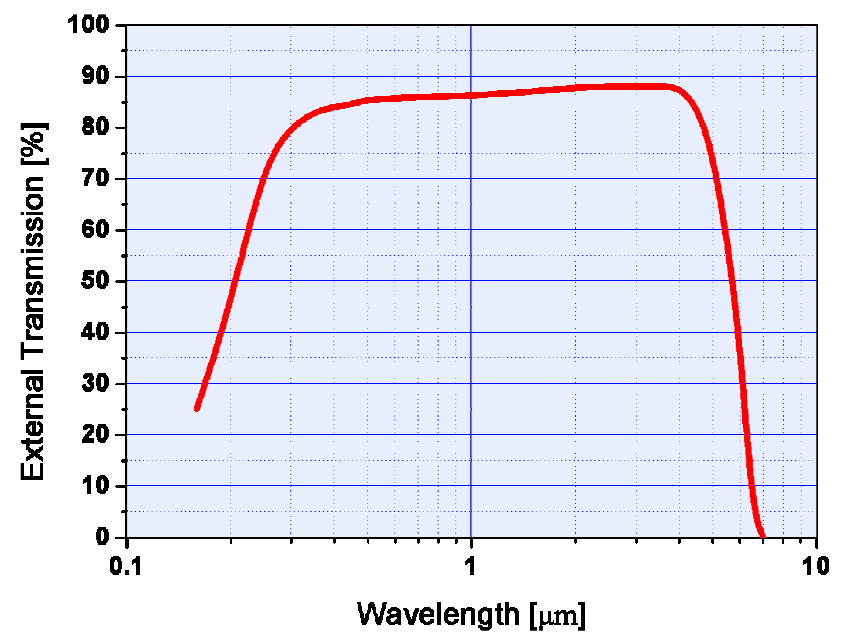

Figure 3. The transmittance spectrum of a $2 \mathrm{~mm}$ thick bulk sapphire wafer produced by the EFG method.

The disadvantage of sapphire fibres over traditional silica-made ones, due to surface defects like growth stripes or variation of fibre thickness, is a higher loss. Therefore maximal length in application is limited, but, on the other hand, sapphire can withstand higher loads without any damage. The light damage threshold is over $1 \mathrm{~kJ} / \mathrm{cm}^{2}$. The parameter of numerical aperture which describes the angle of incidence of the transmitted beam is very high, theoretically even equal to 1 , however, effective values range between $0.1-0.36$.

Sapphire fibres are used in medical equipment, namely in the delivery of the Er:YAG laser beam at 2.94 microns for minor skin and dental surgery. They are biologically inert, non-toxic and have a high laser damage threshold. The resistance of sapphire is employed in spectrometric and pyrometric measurements in harsh environments, e.g., inside chemical reactors, furnaces, combustion engines and in other extreme conditions. At the present time, these are the two major applications for sapphire fibres. However, other sapphire features, e.g., thermal or electrical, could be utilized as well.

\section{Defects in crystals}

We studied our sapphire fibres in an optical microscope with 500× magnification. The defects observed can be divided into two categories, namely i) under-surface and ii) core defects.

There is a very slight vibration in the pulling apparatus of our EFG furnace. This introduces characteristic growth stripes into the single-crystal lattice, cf. figure 4. Accumulations of micro-bubbles may appear in the under-surface part of the fibres, cf. figure 5. These 
inclusions act as very effective unfavourable scattering centres and may cause material destruction in laser applications. This was observed during our measurements as well. When a fibre with a scattering centre was used for laser transmission, it did not withstand the load. The dispersion of the infrared light heated the bulk material locally and eventually the crystal broke apart, cf. figure 6 .
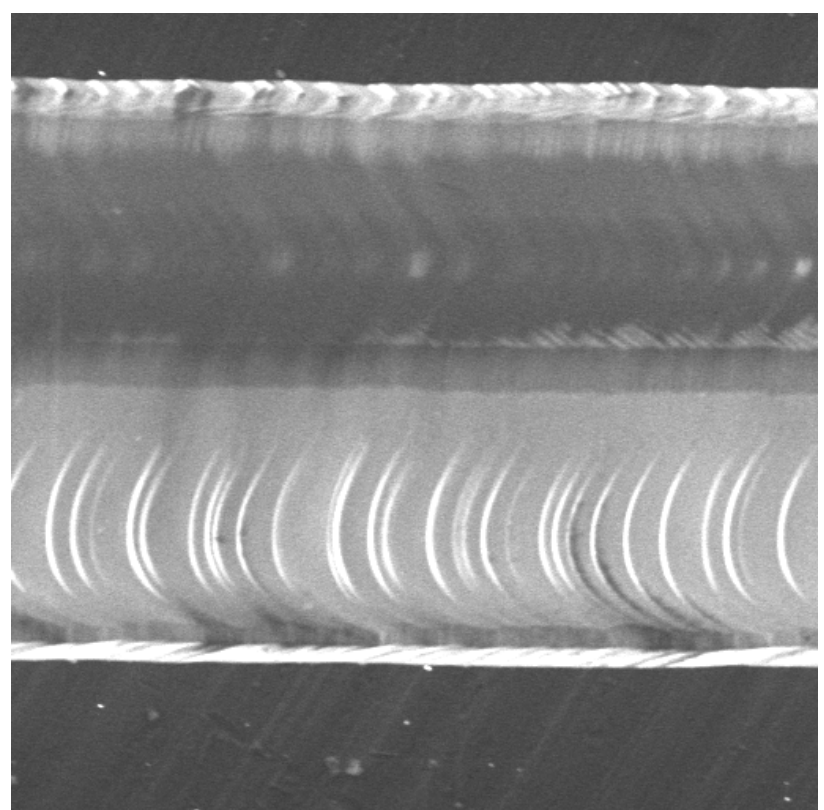

Figure 4. Growth stripes in the crystal structure caused by slight vibrations above the die (BSEM image of $250 \mu \mathrm{m}$ thick fibre).

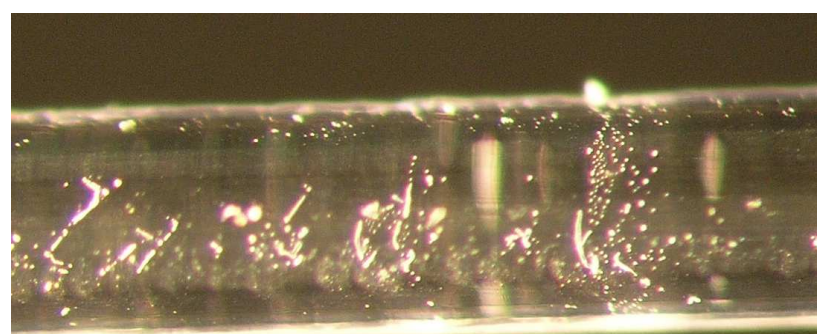

Figure 5. Localized micro-bubbles in the $450 \mu \mathrm{m}$ fibre resulting from a defect on molybdenum dye.

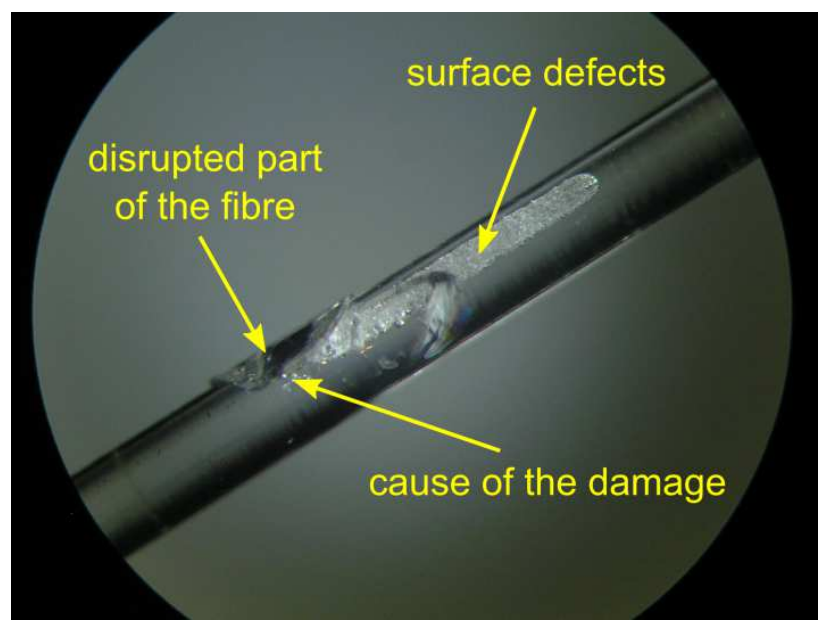

Figure 6. Damaged $450 \mu \mathrm{m}$ fibre after laser measurement.
Another problem we dealt with was the incorporation of molybdenum shavings into the crystal. The content of these shavings decreased with increasing fibre length, $\mathrm{cf}$. figure 7 . We concluded that the fragments originated from the central hole in the molybdenum die as a results of the spark erosion drilling method. By careful preparation of the crucible, orifice and other elements, we managed to eliminate core defects and minimize the content of under-surface micro-bubbles, cf. figure 8 .

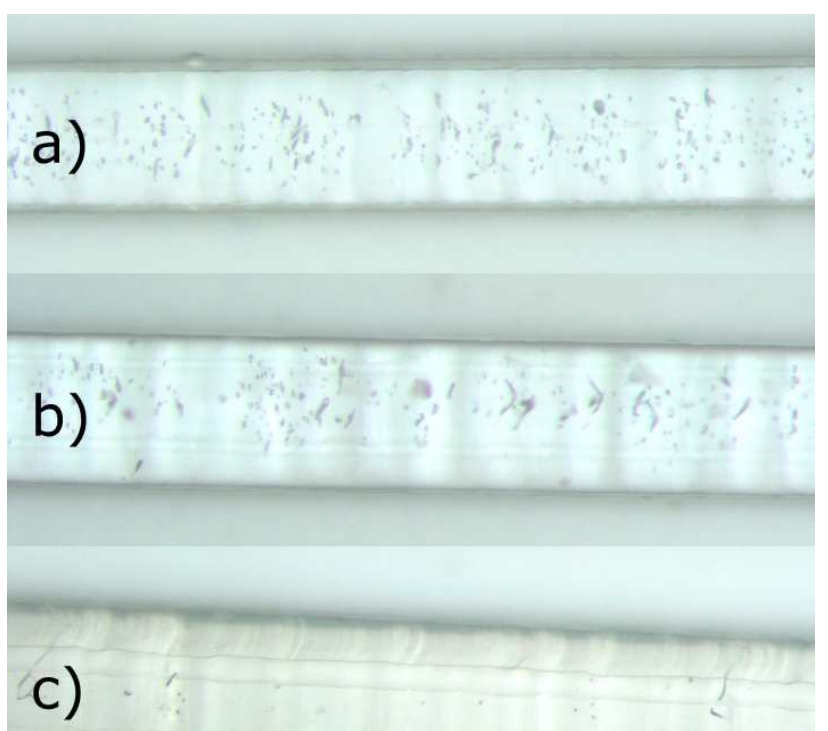

Figure 7. The evolution of the molybdenum shavings content in a long fibre: a) shortly after the EFG growth start, b) after 300 $\mathrm{mm}$ and c) after $1200 \mathrm{~mm}$ of grown fibre.

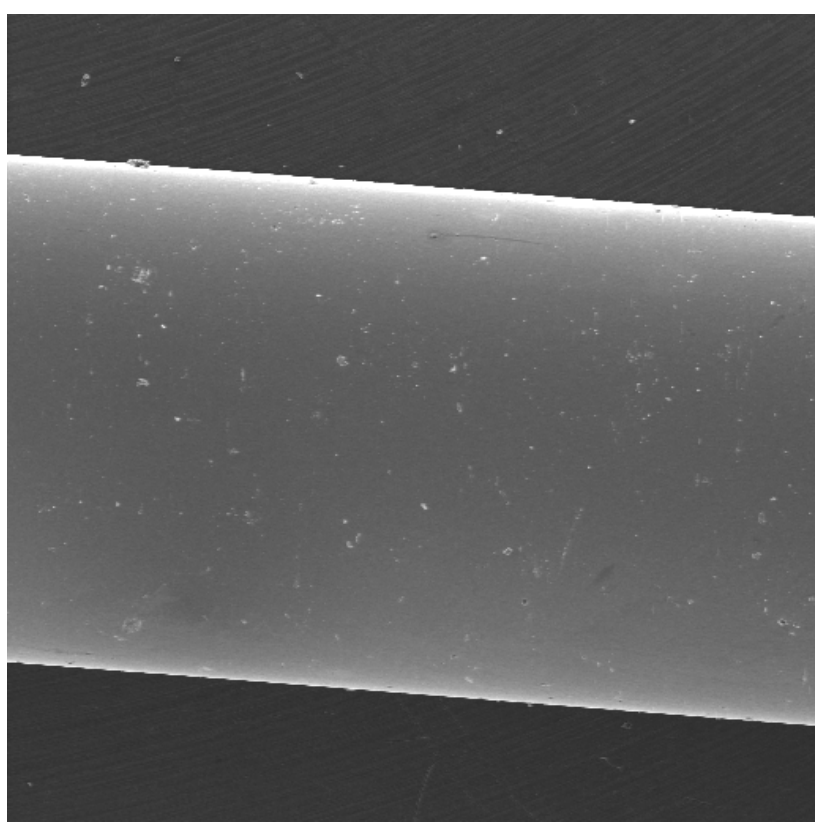

Figure 8. SEM image of a perfect $450 \mu \mathrm{m}$ thick sapphire fibre.

\section{Transmission measurement}

Chosed fibres were polished on diamond abrasive lapping films on both ends. The transmission of Er:YAG laser radiation was measured in our fibres; only filaments 
without defects were chosen for optical measurements. The measurement was conducted for different fibre lengths ranging from 100-160 $\mathrm{mm}$. The wavelength of the laser radiation was $2.94 \mu \mathrm{m}$ and the input energy ranged between 10-110 $\mathrm{mJ}$. The apparatus consists of 1) Er:YAG laser system (frequency rate $1 \mathrm{~Hz}$ ); and 2) focusing optics made of $\mathrm{CaF}_{2}$ lens (transmission at $2.94 \mu \mathrm{m}$ is $94 \%$ ). The parameters of the lens are as follows: diameter $24 \mathrm{~mm}$, thickness $4.1 \mathrm{~mm}$ and focal distance $85 \mathrm{~mm}$. The sapphire fibre was placed in the axial direction, so that the angle of incidence equals to $0^{\circ}$. The whole arrangement is outlined in figure 9.

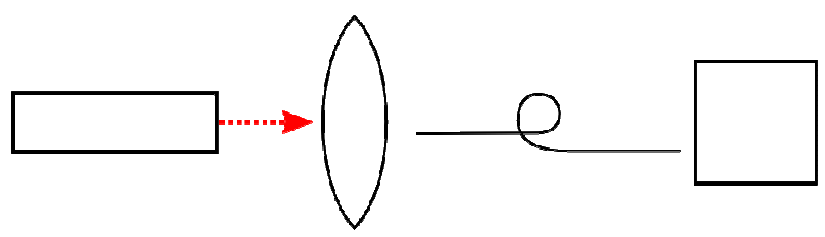

Er:YAG laser $\quad \mathrm{CaF}_{2}$ lens sapphire fibre detector

Figure 9. Scheme of the Er:YAG laser transmission measurement apparatus.

We measured the input energy to the laser system and output energy of the laser beam with a Molectron JD2000 two-channel joulemeter. The detector was a Coherent J25LP-Erbi energetic probe. The spatial distribution of the output laser beam was captured by a Spiricon Pyrocam III pyroelectric camera. The measurements were conducted for different input energies, the values whereof are summarized in figure 11. The end parts of the fibres were treated with a $\mathrm{MgF}_{2}$ antireflective coating. Optical transmission was then computed as a ratio of the output to input energy, including the reflectance on the $\mathrm{CaF}_{2}$ lens surface, which is approximately $6 \%$. Table 1 shows the results of the Er:YAG laser average transmission in the four samples tested. The attenuation was computed to be around $0.1 \mathrm{~dB} / \mathrm{cm}$ (employing the equation: attenuation $(\mathrm{dB})=10 \times \log \left(I_{\text {in }} / I_{\text {out }}\right)$, where $I_{\text {in }} / I_{\text {out }}$ is the input to output intensity ratio).

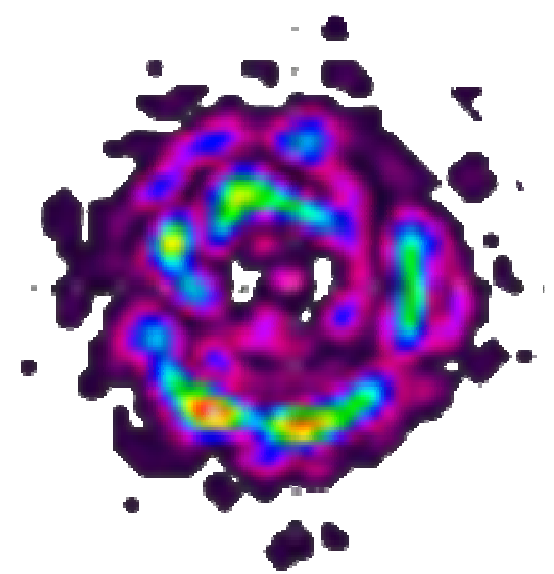

Figure 10. The spatial structure of the output laser beam (Spiricon Pyrocam III); fibre diameter $450 \mu \mathrm{m}$.
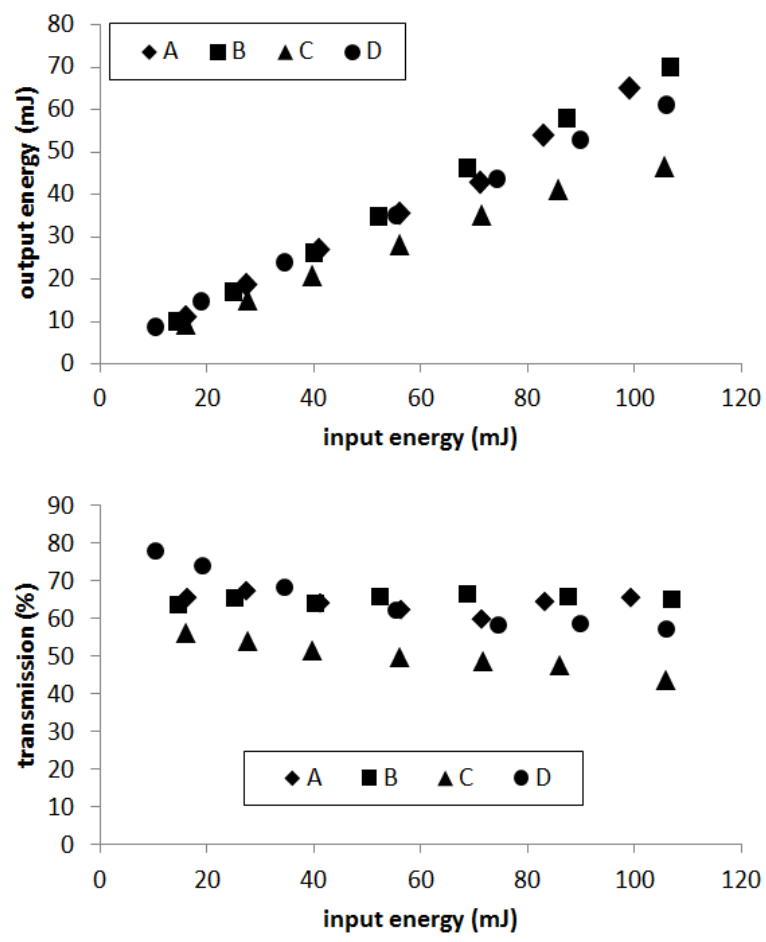

Figure 11. The dependence of Er:YAG laser transmission measurements, the fibre parameters are listed in Table I.

Table 1. List of measured sapphire fibres and their properties.

\begin{tabular}{|l|l|l|l|l|}
\hline fibre & A & B & C & D \\
\hline length (mm) & 100 & 105 & 150 & 160 \\
\hline average transmission (\%) & 63.9 & 64.8 & 50.1 & 64.8 \\
\hline attenuation (dB/cm) & 0.13 & 0.12 & 0.16 & 0.08 \\
\hline
\end{tabular}

\section{Conclusions}

Sapphire fibres are a new promising material for waveguides as well as for other applications. They can be employed in specific environments, e.g. at high temperature or in aggressive chemicals, where traditional materials cannot be used. We successfully produced single-crystal sapphire filaments (diameter (300$500) \pm 10 \mu \mathrm{m}$, length $1500 \mathrm{~mm}$ ) via the EFG crystal growing technique. We observed and described several material defects such as micro-bubbles, inclusions and growth stripes. We conducted measurements of Er:YAG laser radiation $(2.94 \mu \mathrm{m})$ transmission in several of our samples. The attenuation was $0.1 \mathrm{~dB} / \mathrm{cm}$. A thorough comparison of all sapphire fibres from different producers has not been published yet. In general, the LHPG results in better fibre quality then the EFG [10], however attenuation recently achieved in EFG fibres is also close to theoretical values [9]. 


\section{Acknowledgement}

This work was supported by the Grant No. TA01011017 of the TA ČR (Technologická agentura ČR).

\section{References}

1. E. R. Dobrovinskaya, L. A. Lytvynov, V. Pishchik, Sapphire: Material, Manufacturing, Applications, Springer (2009)

2. H. E. LaBelle, Jr., Nature, 216, 574, (1967)

3. A. V. Stepanov, Zh. Tech. Fiz., 29, 382, (1959)

4. P. I. Antonov, Prog. Cryst. Growth Charact. Mater., 216, 63, (2002)

5. B. Chalmers, H. E. LaBelle, Jr., A. I. Mlavsky, J. Cryst. Growth 13/14, 84 (1972)

6. H. E. LaBelle, J. Cryst. Growth, 50, 8 (1980)

7. T. Fukuda, V. I. Chani. Shaped Crystals: Growth by Micro-Pulling-Down Technique. Springer-Verlag (2007)

8. M. R. B. Andreeta, A. C. Hernandes. Laser-Heated Pedestal Growth of Oxide Fibers in Handbook of Crystal Growth. Springer (2010)

9. R. K. Nubling, J. A. Harrington, Applied Optics, 36/24 5934 (1997)

10. J. A. Harrington, in Handbook of Optics, edited by M. Bass, McGraw-Hill (2001), p. 14.1 